
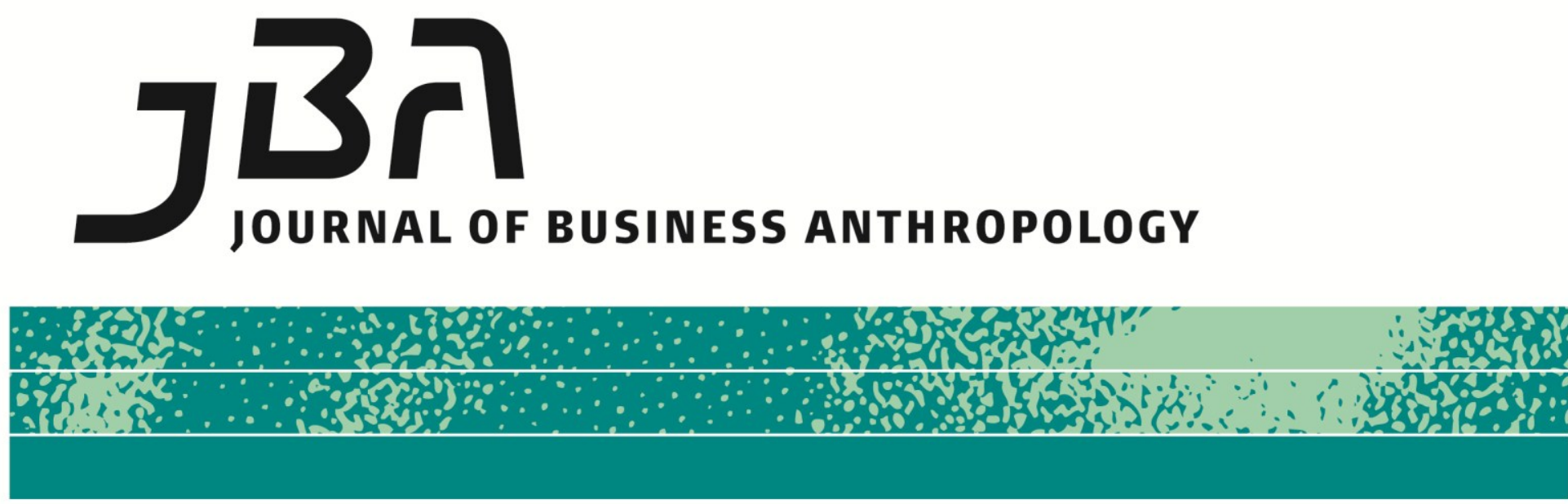

\title{
Anthropology with Business: Plural Programs and Future Financial Worlds
}

Bill Maurer \& Scott D. Mainwaring

\begin{abstract}
How can we imagine and perform an anthropological practice with business, that is, not from a distanced perspective but through a mutual infolding and engagement? How might such an arrangement then be exemplary for novel economic experiments of the kind anthropologists often describe? Reflecting on several years' of collaborations with each other, the authors recount their relationship as an experiment in novel engagements with economic things (money, corporations, universities, accounting principles, computers, etc.) in an industrial and university site. The paper puts forward a theoretical argument about exaptive and nonadaptive plurality that opens new pathways for alternative and sometimes quite conventional values. The context is a specific set of projects around money and payment. The intellectual background is the anthropology of finance and alternative economies.
\end{abstract}

Page 1 of 20

JBA 1 (2): 177-196 Autumn 2012

(c) The Author(s) 2012 ISSN 2245-4217

www.cbs.dk/jba

\section{Keywords}

Money, finance, Intel, ethnography, value 


\section{Introduction}

The occasion of this journal invites reflection on the possible prepositions linking anthropology and business. The first, most obvious, is that a journal of "business anthropology" would concern various anthropological approaches to business, or anthropologies of business. Yet at the same time, as many anthropologists working in industrial and business settings have discovered and even celebrated, working on business often entails working in business (Cefkin, 2009). Gaining access and rapport, the anthropologist works alongside colleagues in industrial settings, participating, observing, and along the way getting caught up in various business ventures. There may still be the assumption, however, that the anthropologist will pull away again, leave the business setting for the academic halls and the journal articles, step outside the temporality of quarterly performance goals or the annual report and back into the slower time of the classroom, peer review, publication and the historical, ethnographic and scholarly archives. Academic knowledge after all is supposed to endure, and to transcend the moment. Business knowledge is for use, in the present or near future: of necessity - and for publicly traded companies, by law - tied to quarterly earnings statements and the fiscal year. An academic article in the social sciences is deemed a classic if people are still reading it in 20 or 30 years. A corporation's long-range product roadmap may extend, at most, 10 years, and in many industries its time horizon is much shorter. Business and anthropology inhabit different temporal horizons.

In this essay, however, we reflect on another temporality and another prepositional relation of anthropology and business: anthropology with business. "With," for us, implies an ongoing relationship, the entanglements of kinship and alliance more than observation or canned participation. We speculate on our own collaboration as a process of being drawn into relation with each other's projects and perspectives, an exchange which, while not altogether mutual or equal, not without its frictions and contradictions, nevertheless has opened up plural possibilities for our own work, for the work of others around us, and for our respective institutional locations (in the largest public university system, and in a gigantic publicly traded IT company). Because our collaboration is about money - what it has been, what it is becoming, what it might be in the future - it contributes to specific plural and diverse economies for money, for finance, for knowledge production. This essay is thus an anthropology of finance. It is about our own relations of credit and debt with each other and between our respective institutions, and the parallel movements we have been tracking of alternative financial and monetary practices and technologically-mediated means of value transfer. The business propositions of the products we have been involved in are all related 
directly to new financial systems and new technologies of money. One of the aims of our work has been to bring to scholars' and start-ups' attention the back-offices and hidden infrastructures of money. And along the way, our collaboration has resulted in novel institutional arrangements for the financing of research in academia and industry, arrangements that brought others into our orbit and these back-offices of money and payment.

Payments innovations are not unrelated to the financial crisis. Coincident with the financial crisis has been both the decline in the use of credit cards and the rise of prepaid instruments, on the one hand (Jacob \& Lunn, 2011), and the explosion in social media, on the other. The payments industry itself is shifting from being primarily based on a business model that relies on interest and credit, to one more centrally concerned with fees and, increasingly, access to transaction data. In the consumer finance domain, "bad bets" (on subprime mortgages, on riskier clients) are giving way to "big data" (World Economic Forum, 2011).

The anthropology of finance as a field is roughly coincident in time with our collaboration: we began thinking together about various technological futures for money at the same time that Maurer was compiling several review essays of disparate anthropological studies in financial spaces and worlds (Maurer, 2005; Maurer, 2006). A couple of anthropologists were just completing their dissertations on financial topics (Ho, 2009; Zaloom, 2006). Science and technology studies (STS) scholars who had begun to investigate finance were reaching out to anthropologists, and "social studies of finance" (SSF) was developing as a subfield at the intersection of sociology and STS. Sociologists and STS scholars associated with Michel Callon, Bruno Latour, Donald MacKenzie and David Stark had just founded the Association d'études sociales de la finance (AESF) in 2000. Stark hosted a conference in 2002 at Columbia that brought many of the "social studies of finance" scholars together. But the real origin point of the AESF was the collaboration of a group of interdisciplinary Parisian graduate students (Muniesa, Lepinay, Godechot, Tadjeddine, deBlic and Grossman among others) without the involvement of senior scholars. The Socializing Finance blog was initiated in 2007 by Daniel Beunza and Yuval Millo who are of the same generation. It was only later that social studies of finance became narrowly identified with 'performativity' and with established names like Callon, Stark, Latour and Mackenzie. ${ }^{1}$

${ }^{1}$ Personal communication, Martha Poon. As with many interdisciplinary endeavours, anthropology's contribution had been and to an extent remains its signature methodology, ethnography, as well as its knack for defamiliarization. 
Also coincident with our collaboration was the global financial crisis that began in 2008. Indeed, one of the major "outputs" of our collaboration, a conference titled, Everyday Digital Money," took place just as the foundations of Wall Street were shaking. Anthropologist Keith Hart, our keynote on 24 September 2008, just 9 days after Lehman Brothers failed, threw out his prepared remarks and spoke off the cuff about the growing financial calamity. Since that time, anthropologists have assumed public roles in the debate over finance. The Financial Times' reporter Gillian Tett, an anthropologist by training, became a leading guide through the unfolding debacle and became herself a topic in the academic debates over how to study finance (MacKenzie, 2009). Karen Ho's well received book chronicling the lives of financial professionals during an earlier crisis garnered her several televised media appearances. David Graeber's (2011) book, Debt: The First 5000 Years, hit the bookstores and barricades as the Occupy Wall Street movement took to the streets.

These are just a few examples of the public face of the anthropology of finance since the crisis. In other quarters, anthropologists have worked behind the scenes, with regulators, financial engineers, investors, and start-up companies. Our collaboration is one example, and it spawned others, as we discuss below. Also behind the scenes have been the intellectual disagreements within this nascent scholarly community. While some make bold pronouncements about Crisis, Financial Abstraction and whatnot - we will not cite any names here - and others (Roitman, 2013) seek more modestly to correct them, another couple of debates have been taking place under the tent. Donald MacKenzie's (2009) review of Gillian Tett's (2009) book helped crystallize one, and Annelise Riles (2010) made another, related debate more explicit. These debates are instructive for thinking about anthropology and business collaborations like ours, so, before detailing our own work as an emergent economic actor of a particular sort, let us briefly review those debates.

First, have the SSF scholars and anthropologists "gone native?" That is, in their careful dissection of the methods, tools and calculative rationalities of financial practice, have they lost sight of the larger picture of expropriation, inequality, instability and crisis? If one starts from the assumption that all financiers are bad, then the nuanced accounts of the lives and tools of the bankers and traders are apologias for their recklessness and immorality. Is "good," that is, prudent, morally sustainable finance, possible? Those like MacKenzie and Tett who would answer yes have faced criticism from more Marxist colleagues. The

\footnotetext{
${ }^{2}$ http://emoney.typepad.com
} 
Socialising Finance blog had a discussion on this exact topic after a 2010 conference in Paris restaged what has become a familiar debate: the political economists accuse the SSF scholars of getting lost in the technical details of finance to the detriment of political critique. ${ }^{3}$ This is clearly a concern in any anthropology/industry collaboration. Such collaborations can allow a degree of access that makes it easier to get caught up in the technicalities to the detriment of seeing the "larger picture."

Second, related to the first, has the focus on technical procedures and financial models placed the focus on the technoscientific aspects of finance to the neglect of the legal, regulatory, and politico-ethical worlds that create the playing field for finance? If one focuses on the technical aspects of their work, then the contracts, documentary practices and political battles about regulation get sidelined - and here is a place where anthropology might actually make a difference (Riles, 2011). Ironically, however, because of this stance Riles has similarly been seen as too cosy with finance, not critical enough, or participating in finance's own obscurantism. It seems you just can't win in academic fields predicated on clear lines of demarcation between analyst and subject of inquiry, where "impurity" still means "danger" (after Douglas, 1966). This is unfortunate, and speaks to a larger failure of critical imagination. Riles's work seeks to capture an analytical language and practice that would accept, with the possibility of transforming, the world-changing potential of the tools that build financial architectures. It offers a politics without guarantee - and this is what is most disturbing to people who still dream of a simpler, Manichean world of good guys and bad guys. In a time when all our lives are bound with finance, a strictly denunciatory position is difficult to sustain.

Anthropological and other social research on finance had accurately charted the risks of the shadow financial system of derivative trading and other off-balance sheet activities (Green, 2000, Pryke \& Allen, 2000, Maurer, 2002), the problems inherent in the mortgage market in the United States (Langley 2008), as well as more general issues around securitization (Maurer, 1999). All before the crisis hit. Normative claims about the evils of finance cannot take the place of empirically rich, analytically informed research on financial actors, institutions, formulae and their effects. If it feels like going native, then either we are in the good company of some of our anthropological

\footnotetext{
${ }^{3}$ Daniel Beunza provided a perspective on this Paris conference on his blog, Socialising Finance. See http://socfinance.wordpress.com/2010/05/21/political-economistsdenounce-social-studies-of-finance-for-overlooking-the-political/
} 
forebears, or we are striving for a form of collateral, collaborative praxis that might hold hope for a new financial future (Riles, 2011, Miyazaki, 2007, Jensen \& Winthereik, 2012, Gad, 2012, Holmes \& Marcus, 2008).

The SSF and Riles approaches both ring true to us, perhaps because of the financial/intellectual/institutional intertwining that we discuss here. We do not see them as opposed so much as aspects of different facets of practice. In other words, from our vantage point, they are both "correct" insofar as they accurately map the worlds we have inhabited together in our collaboration. In writing of the forms of collateral knowledge that undergird contemporary finance, Riles, like Maurer (2005b), finds a collaborative endeavor, and sees in it the possibility for new, joint work actually to reimagine aspects of the financial markets and financial regulation. As she writes on her blog, itself an effort to address and invite in new audiences with which to begin to think together with: "Thinking together about theory and practice can produce kinds of insights and solutions that neither side could imagine alone. Of course how to do this, when the temporality, the standards of evaluation, and the political pressures of our careers as thinkers in the academy or in government or in the market are so different is not easy. Working through these challenges is its own challenge for our field". ${ }^{4}$

In what follows, we document our own collaborations over the past 5 years - how they emerged, evolved, shifted, expanded, contracted. We discuss how, in seeking to delineate and understand "alternative" financial and monetary practices - that is, self-reflexively oppositional ones - we became an instantiation of what we had set out to discover. This has implications for understanding financial and economic worlds as plural and diverse rather than reducible to one logic or set of practices. Critics like those we have alluded to will undoubtedly see us as Pollyannaish at best or coopted dupes at worst. But we ask that such critics forestall judgment for now, if only to be able to take us - at first - as an object of inquiry, worthy of deeper investigation. As we came more and more into contact with alternative financial worlds and especially new payment infrastructures, and as our work impacted how others were understanding, designing and deploying those infrastructures, the very idea of one logic became impossible to sustain.

\section{Reading Gibson-Graham at Intel}

\footnotetext{
4 (http://collateralknowledge.com/blog/2012/01/broadening-the-methodsfor-studying-financial-regulation/)
} 
One day early in 2007, Mainwaring came to visit Maurer in his office at UC Irvine. He was accompanied by Hsain Ilahiane, an anthropologist currently at the University of Kentucky who was spending a year as a "Visiting Researcher" at Intel. The encounter was unexpected (by Maurer, at least). Mainwaring had come to talk about money. Maurer had just completed a review essay on the anthropology of money (Maurer, 2006). And Mainwaring was just beginning a project through Intel Labs' Peoples and Practices Research (PaPR) group on "everyday digital money." Over the course of the discussions that ensued, the project's title was renamed "Personal Digital Money." We will not go into the details here, but suffice to say that Mainwaring was engaged in an attempt to shift the conversation at Intel about digital and electronic forms of value transfer, away from just being about security and efficiency, and toward the actual uses to which people were putting new electronic forms of payment, and their broader cultural context. Included in this was an opening-up of the conversation at Intel about money itself - an open-up that Maurer had also been simultaneously trying to facilitate in anthropology (see e.g. Guyer, 2004: 175).

What was happening at Intel Labs at the time was a willingness to experiment with different disciplines and methodologies. Having Ilahiane formally ensconced at Intel as a Visiting Researcher was an example of this experimentation, since normally such visitors would have been engineers or computer scientists, under short-term consulting contracts. This was not taking place at Intel writ large, but in small corners of it, like PaPR. The effort to open the door to nonengineers at Intel has precedent in institutional novelties like Xerox PARC, famous for inventing the giant green print button on photocopy machines as well as graphical user interfaces that gave rise to the Windows and Apple operating systems. PARC brought social scientists into the fold, notably, Lucy Suchman, whose Plans and Situated Actions: The Problem of Human-Machine Communication (Suchman, 1987) quickened intellectual and design activity around the new field of human computer interaction (HCI). Also in the early to mid-1980s, the Associate for Computing Machinery (ACM)'s "social and behavioral computing" group reorganized itself as the Special Interest Group in Computer Human Interaction (SIGCHI, or simply CHI), whose conferences became important venues for a new approach to computing that placed human interaction, culture and society at the center of analysis.

At Intel Labs, as elsewhere in industry, HCI permitted a new flexibility in the approach to computing and design problems. But it was atheoretical. Or, rather, it was not specifically bound to any particular theoretical approach. "Theory" was something to be brought in to spark new conversations but not necessarily new commitments. Intel has a 
history of this kind of engagement before Mainwaring's work with Ilahiane and Maurer. Under the Visiting Researcher model, academics like Ilahiane got to sit in the cubicles and conference rooms while also serving as ethnographic guides for Intel researchers in the field. This model was based on an explicitly longer-term time frame than a simpler consultancy agreement, with one year at least being committed to the corporation in exchange for a salary and a different kind of research experience than the ordinary academic sabbatical.

As part of the Personal Digital Money project, Maurer's role was different. It was a short-term consultancy. Maurer's job was to bring "theory" in this open-ended fashion to Mainwaring's group. This made it fun for Maurer - the opportunity to engage in an unfamiliar institutional space with, as one of us put it, "very adult undergraduates." It made it fun for Mainwaring, too - the opportunity to stretch his wings and think outside the boxes of the engineers. But it was challenging. It was hard for Maurer always to know what was happening on the Intel side. It was hard for Mainwaring to fit the activity into the accountability frameworks the industrial organization required, harder than, say, providing a back-to-office report (BTOR) after a short stint of corporatestyle field research of 2-3 weeks. We will return to these points in the next section.

At the start of what would become their long-term collaboration, Maurer spent several days at Intel Labs outside of Portland, Oregon, running a small seminar with Mainwaring and one of his colleagues, Wendy March, a design researcher. Ilahiane dropped in and out from time to time, but he was involved in some other projects at the time of Maurer's visit. Hovering in the background was Maria Bezaitis, Mainwaring and March's then-supervisor, who prodded us to create a material record of our discussion and to sharpen our theoretical focus. For Maurer, the initial encounters were strange: it was hard to figure out what this lab and this activity in the lab was for, how it contributed to Intel's business of making silicon chips; it was also hard to figure out the supervisory relationships and the expectations among everyone. For Mainwaring, the stakes were higher: this was his job, after all, and he had to answer to supervisors. The "collaboration" did not always feel mutual, harmonious, or truly collaborative.

Social scientists at Intel usually focus on bringing their methodological toolkits to the table: how to design and implement semistructured interviews, how to take ethnographic fieldnotes, how to see differently in the field. Maurer brought a reading list of work in the anthropology of money and the social study of finance. We engaged in three days of discussion. We recorded the conversation and used Intel's resources to have it transcribed. Some of what follows captures the dialogue we were starting to have. The topic was alternative economies 
and alternative forms of money and finance. Mainwaring had a vague sense that understanding "alternative economies" could help differently enframe emerging electronic money systems than Intel's standard focus on such matters as processing power of encryption. Mainwaring and Ilahiane had just completed some fieldwork on the brand-new mobile phone-enabled money transfer service, M-PESA, a product of Kenya's main telecommunications provider, Safaricom (see Mas \& Morawczynski, 2009, Jack, Suri, \& Townsend, 2010, Kuriyan, Nafus, \& Mainwaring 2012) and related projects in South Africa, and had explored Islamic conceptions of debt and credit in Morocco. Mainwaring and March had also done work in Japan on the use of nearfield communications (NFC) smart cards that are used for transit but also for small purchases, and were exploring new online-based lending and sharing communities like Kiva.org and a Time Banking community in Redmond, Oregon. Maurer's reading list included works by scholars writing about Local Exchange and Trading Systems (LETS), ${ }^{5}$ as well as writing on alternative economies, non-economic uses and meanings of money, and theoretical work that seeks to question the verities of economic theory (mainly from geography).

So first we start with alternative. What is alternative?

What is alternative. Different notions of alternative. So alternative in the sense of alternative to the formal economy which would just mean the informal economy or alternative in the sense of alternative to the whole notion of there being an informal or formal economy in the first place?

This was [INAUDIBLE]?

This was in the Williams et al. ${ }^{6}$ And Williams et al basically say that while for some participants LETS systems help them get into the formal economy you know they learn some skills and then they can get a job or it actually employs them and they have a real job. And while for others LETS systems were helping them to kind of almost formalize what already existed as an informal economy. For most of them they weren't in it for either of those

\footnotetext{
${ }^{5}$ Local Exchange and Trading Systems (LETS), the brainchild of Michael Linton, are formalized barter networks that employ a software platform to keep track of trades within the system. Linton was one of the other keynotes at Mainwaring and Maurer's Everyday Digital Money conference in September 2008. Mainwaring was interested in LETS as well as Time Banking as alternative means of economic value creation and exchange, and the fact that they rely on information technology made them potentially more legible to Intel than other alternative financial arrangements.
}

6 The text we were discussing was Williams, Aldridge, \& Tooke, 2003. 
reasons. They were doing it for the pleasure of community and connection.

So it was a step towards the formal but then also?

For some it was a step towards the formal but for some it was a way of formalizing the informal. Also enriching the informal because we could draw more people into it then too. But for many it was really the importance was to one side of the formal/informal business altogether. It wasn't about economy or making money or anything like that or even I need someone to babysit my kid. It wasn't about that. It was just about creating a diffused sense of social connection, and meaning and obligation and community and local identity.

This is a snippet of the kinds of discussions we had. Running throughout, the work of J.K. Gibson-Graham (Gibson-Graham, 2006) served as a kind of touchstone, helping to orient us toward the possibility of what they call plural and diverse economies. Here we were discussing Jane Guyer's ( 2004) reformulation of Paul Bohannan's (1959) classic article on the Tiv multi-centric economy. Maurer was describing how he teaches Bohannan and Guyer to his undergraduates: Start with Bohannan, then:

Then give them her [Guyer]. And so once their minds have been blown by the possibility of multi-centric economy, she takes that and opens it up and says, aha, but this multi-centric economy actually only works in relation to the external linkages that it had with Europe.

Mmm-hmm.

So then [...] maybe [the] western European derived economy isn't as homogeneous, blah, blah, blah as we think. Enter GibsonGraham. [...] you can see how you can sort of, it helps you sort of open up an argument about economy and give you another sort of set of conceptual tools then to think about it.

Mmm-hmm.

Along the way, this all led to the idea for an internal white paper that would be circulated at Intel. Again, Gibson-Graham were central:

The more immediate thing is we wanted to do an internal white paper, where we can put up on the internal website for people saying, "Okay you've spent...you know six months now on charity, purity, community, why should Intel care?"

Uh-hum

And that's...I think with the paper... 
Yeah, yeah. I mean even what's....what's here, even before we started talking there was a narrative in a paper, right? And with some of the stuff we talked to today, there's more of...you know in a way a framework that consists of series of matrices. But then that speaks to some of this charity literature and some of this sort of diverse economy literature. I'm not sure which one is the white paper? You know or which piece is the...'cause this...the narrative here you could imagine being sort of the flesh, like the ethnographic meat on an academic paper that starts from Gibson and Graham and sort of gives a matrix of charity and giving and all the mechanism and means and modes or whatever. Or this could be a white paper all by itself, I don't know, I don't what the form of white paper is...is, you know.

Well internally it's whatever we want to make up.

Yeah.

It's just something to...so what concerned me is...that I haven't written the damn thing, it's way overdue. But it'd be short...people have short attention spans here, they want it to get to the point quickly, they don't want...they want novelty. They want non-obviousness.

Yeah.

So I want to...so one cut is...you know top level, "I want to blow your minds Intel!"

We decided we would write a paper called, How Do You Hear Theory? Or, Reading Gibson-Graham in Industry. We submitted an abstract to the Ethnographic Praxis in Industry (EPIC) conference. It was not accepted. Another paper of ours, based on Mainwaring and March's research in Japan, was accepted at CHI, and went on to win a best paper award (Mainwaring, March, \& Maurer, 2008). We never wrote the first paper. But the abstract for that never-written paper is instructive, now, for thinking about anthropology with business in the domain of money and finance. Our abstract read:

What does it mean to hire someone to "be theoretical?" This paper reports on a collaboration between industry and academia in which an anthropologist was invited into an existing collaborative group not to provide methodological expertise but to prod the group with theory. In this case, the anthropologist introduced the group to theories of alternative economies. This included the work of J.K. Gibson-Graham, a scholarly personality made up of two distinct individuals - Julie Graham, an economist, and Katherine Gibson, a geographer. Gibson-Graham criticize/s unitary or homogenous accounts of "the economy," 
instead offering a vision of proliferating, diverse "economies" not captured by standard or critical analysis of capitalist social formations. By bringing Gibson-Graham and other theorists to a group discussion about diverse and plural economies, the collaboration permitted the hearing of theory in a context that mirrored the form of that which the group was investigating. Hearing theory did not just mean finding an existing framework to help sort out data, but opening the conversation to new ways of thinking and representing. In some ways, the theory brought to the table was the least appropriate for an industry setting because of its denseness. While academic collaboration in industrial work is not new, this one is unusual because of the location of an academic as theory-bearer rather than methodology-sharer. Anthropology in industry has often meant ethnography as a tool or a means to an end. Here, however, anthropology means listening to theory, not mining for methods. As such, the collaboration about diverse economies participates in a diverse economy of its own: unlike methods, which can be transported, adapted and put into play in new contexts, the uses of theory are rarely self-evident at the start and the ends are uncertain. This requires that theory be heard differently. And hearing theory in industry may also work to shift the conversation about the uses of theory in the academy, as well. It has the potential to soften or altogether obviate the divide between "theoretical" and "applied" work while finding new hybrid industry/academic spaces within which to do and hear theory.

Years later, in 2011-12, other colleagues of Mainwaring's, at Maurer's instigation, began reading Gibson-Graham, this time in relation to questions about Intel's supply chain and its relationship to some of its suppliers. They are discovering all kinds of relations beyond "the give and the get" (as one puts it) of market transactions. And in many ways they are inhabiting a different world from where we were in 2008, one where Chinese suppliers are central to IT manufacturing, where new disruptive entrants like Facebook and Google are starting to occupy the platform provision role that had been Intel's mainstay, where Intel's own "ecology" of businesses (Moore, 2006) and services is no longer centered on Intel itself but dissipates into a proliferation of start-ups fed by venture capital, angel investors, philanthropic capital, and prize competitions, these last two at least relative novelties in the financing of industrial activity. The animating problem, however, was still similar to what it was for us in reflecting on what we were doing back in 2008.

\section{Diversity, Variation and Adaptation}


One of many ironies is that we never really did deal in a sustained way with Gibson-Graham. Their work was successful in motivating us and inspiring us, but we never engaged with it in a deep, theoretical way. We were not reading the work the way they had intended it to be read. In our Intel seminar, it wasn't really clear to Mainwaring and March why we were reading it except that Maurer was supposed to be bringing "theory" to the table, and here was "theory" embodied in GibsonGraham and some other articles and books. No matter how ethnographic these works may have been, they were to be read for their "theoretical" content, not least because this was the directive given to Maurer, to bring "theory" to Intel. Since the reading was not tied to a concrete activity "in the field" or specific analysis of data previously collected, it felt like we reading for the love of reading. This seemed to go against the surrounding institutional context and prescripts. For example, we also needed credibility within Intel. There was to be an Intel Open House where the Personal Digital Money project would be presented to the wider Intel community. We needed an image that would capture what we were doing. We took Gibson-Graham's diagram of the "Economic Iceberg" (see Gibson-Graham 2006). The point of the economic iceberg is to show that most accounts of economic activity, whether critical or not, focus on wage labor in the capitalist firm as the paradigmatic mode of value creation and expropriation. This is only the tip of the iceberg one can see above the ocean's surface, however. Below the water line, a whole profusion of economic activity is going on, sometimes articulated to what is happening above water, but very often not. Gibson-Graham sought to uncover and describe a proliferation of diverse and plural economies irreducible to one logic or form. They invoked one version of Darwinian evolutionary theory that emphasizes variation rather than teleology: Stephen J. Gould's spandrels and "exaptations," not Richard Dawkins's "adaptations."7

The open house was about visibility and tangibility. It was important to have ideas visually communicated about the project, and the open house was an important thing in terms of managing Intel's expectations. What were Intel's expectations? That the activity we had been engaged in was "research," that the team had "academic partners," and that the academic partner had access to the kinds of economic alternatives and value formations Intel was interested in. It was also important that the academic partner was credentialed in a way that is legible to Intel.

In doing this dance of accountability, of course, we ourselves exemplified Gibson-Graham's argument, and doubly so. First, adding accountability in this fashion "formalized" our own intellectual and

${ }^{7}$ See Gould \& Lewontin, 1979 and Gould, 1991 on this debate. 
monetary exchanges (insofar as Maurer's consultancy contract animated, authorized and formalized both), placing us above the water line of the economic iceberg, looking down beneath the surface at the supposedly more social, "authentic," more "real," less formal, alternative forms of value creation and exchange.

But second, what we did ended up being an example of what Gibson-Graham described as taking place below the water line: an experiment in novel engagements with economic things (money, corporations, universities, accounting principles, computers, etc.). For Mainwaring had hoped that he could lead specific interlocutors at Intel to reflect on new relationships of ownership. Academic partnerships at Intel were not new, as we have noted. But ours was a little different in its reflexivity. We were suggesting that Intel could think differently about the value that corporations get from academic research beyond, say, the leakage of intellectual property. The latter has been traditionally the corporation's chief concern with such collaborations. And we were talking about, bringing to light at Intel, alternative economies while unintentionally becoming one ourselves. We were creating in our own collaborative relationship just such an alternative. We were becoming an instructive example of what we were talking about.

Still, however, labs are tracked by how many invention disclosures they generate, because they can be counted - not at all unlike publications for academics. Mainwaring's Intel colleagues wanted ideas and theory, and to explore at a deeper level the complex realities of diverse forms of value and economy. At the same time, they were always aware that this was a consulting contract with specific deliverables that fed into a larger audit culture about demonstrating in the right way to the rest of Intel that we were doing "research," and the right kind of research.

For Intel, the discovery of economies below the water line potentially has "real" value apart from protest or opposition to a dominant economy or value formation. In money and finance, our work helped tell a different story, about a system that could make, handle, manage money and finance in a more humane way, or to serve human agendas. Our project was also legible to Intel in that it served Intel's aim of trying to predict the future, to envision change before it happens, and to see how random mutations open up new pathways. Here, Gould's spandrels meet Dawkins's adaptations, as every potentially nonadaptive element may open up new channels or paths for future value(s).

\section{Becoming-With Business and Finance}

While we were working out our own collaboration with each other and with Intel, we were also becoming actors in the infrastructures of 
payment systems. Immediately on the heels of the Personal Digital Money project, Maurer founded a research institute devoted to new mobile phone enabled payment systems, the Institute for Money, Technology and Financial Inclusion (IMTFI; see Schwittay, 2011). It is funded by the Bill and Melinda Gates Foundation. A program officer found out about Maurer's work on money through another Intel colleague not connected to the project with Mainwaring. Mainwaring serves on the board. The institute's mandate is to create new partnerships with other academic and research institutes in the global South, to foster their own research agendas within an overarching rubric around new technologies of payment and banking. This, then, led to new collaborative relationships with industry. It was striking to Maurer at least that industry participants at the Everyday Digital Money conference found it really difficult to figure out how to collaborate given the constraints of non-disclosure their employers set upon them. They discovered in the academic setting a space of (relative) freedom to find new ways of talking to each other. This became one of the raisons d'etre for the institute, written into its subsequent funding applications. Providing industry researchers a space of freedom to pursue their own priorities ended up being built into the institute's mandate. For example, one industry researcher, in the process of switching jobs, sought funding from IMTFI for research in Afghanistan. As Maurer wrote in his proposal for IMTFI's funding renewal:

This project demonstrated the value of providing support to industry professionals outside of their regular work - and thus not subject to any restrictions that might be placed on them by their employer. It created new audiences for IMTFI research and helped inform these audiences about specific elements of the financial inclusion agenda that had been opaque: from the basics, like the costs to the poor of dealing exclusively in cash or gold, for example, to more specific issues like the need to devise SMS/USSD 8 interfaces and the need to consider how funds in a mobile money system are backed and how the float is managed. For example, at a public presentation of the Afghanistan research, several audience members commented via Twitter that they would require additional training in how to program for SMS applications if they intend to get involved in this space, rather than focusing on the operating systems of high-end smart phones (like the iPhone's iOS).

8 SMS, short message service, refers to the basic text-message capability of simple mobile phones. USSD, unstructured supplementary service data, refers to an even more basic protocol that allows the phone to communicate with the mobile carrier's towers. 
This snippet from the proposal shows both the justification of supporting industry researchers in terms of providing that space of freedom, and the unintended effects of doing so (written here as if they had proceeded exactly according to a preordained plan!). Note that those effects included opening up into mobile financial services the idea of programming in "old" languages in order to design new services, a reaching below the waterline, perhaps, of Gibson-Graham's iceberg, into oddly non-market, "merely" operational protocols like USSD, or delving more deeply into the weirder aspects of "market" relations like the funds float in a mobile money system. ${ }^{9}$

With a design colleague, Camellia George, Mainwaring produced a video (and comic book) imagining a world of future moneys and finances where people would use multiple public and private currencies simultaneously and in conjunction with one another, in arrangements with merchants providing loyalty discounts, and with alternative financial institutions, banks and brokers offering savings and investment products. ${ }^{10}$ For 2008, it seemed far-fetched. In a world where a social networking service, Facebook, now offers prepaid credits, where there is open speculation that Apple will buy a bank, and where personal, transactional data is becoming a new coin of the payments realm, it was prescient. In the context of our work, we have been able to interact with both the platform development side of mobile payment systems, and the regulatory side (see, e.g., Kendall, Maurer, \& Machoka, 2012).

Independently of this, our collaborations with others at UC Irvine and Intel Labs have resulted in another institutional/financial arrangement, a research center devoted to "Social Computing,"11 harking back to the old pre-CHI "social and behavioral" moniker but distinctly different in orientation. Where CHI's progenitor emphasized the gap between the human and the computer, the paradigm of social

\footnotetext{
${ }^{9}$ It is beyond the scope of this paper, but the float in mobile money systems the funds held on behalf of all the clients using the service who have uploaded value into their accounts - is generally not allowed to be intermediated. That is, the float cannot be leveraged by the mobile network operator (i.e., the operator cannot earn interest on it) nor can the operator use it for any of its regular expenses. Regulations in many countries demand it be placed in a special kind of trust account, thus removed for a time from capitalist economic relations. This is an alternative economy within the mobile money economy.

${ }^{10}$ See Navigating Future Moneyscapes, http://www.youtube.com/watch?v=7yT4q_ykGl4 and http://emoney.typepad.com/blog/2008/07/navigating-futu.html

${ }^{11}$ See http://socialcomputing.uci.edu
} 
computing we are now seeking to formulate focuses on the entanglements. Our own entanglements in a way provide inspiration.

How can we assess the multiple engagements with economic things that is our ongoing collaboration? This brings us back to the debates over the anthropology of finance, and to a prepositional commitment to anthropology with business. Isabelle Stengers draws on Gilles Deleuze's "thinking par milieu". The double entendre captures both the middle and the surround. "Through the middle' would mean without grounding definitions or an ideal horizon. 'With the surroundings' would mean that no theory gives you the power to disentangle something from its particular surroundings" (Stengers, 2005:187). We are both in the middle and not capable of being disentangled from our habitat, the surround that we ourselves have helped co-constitute and in which we operate. At the same time, there is no easy merging of perspectives or positions here: we both still occupy our separate institutional locations, with their demands, pressures, mandates at cross-purposes, divergent temporalities, and so on. We "intervene in [each others'] ethos" (p.189), one might say. And in that intervention, we format financial and monetary relations for each other, for the world of payments around us, an exaptation that nonetheless opens up multiple and diverse pathways.

We would like to think that what we are doing matters at this historical juncture, too. There are at present critics on the left and right - and far right and far right - arguing for the end of credit altogether, for the demise of state-backed currencies, for no final settlement on the one hand and for a nostalgia for "community" on the other, that risks sliding into the most reactionary forms of exclusion. The public sector is eviscerated, and the additive ecology of money and finance we were looking at back then at Intel, is now looking more and more like a supplantive, competition-driving-out-alternatives ecology where private currencies and payment systems actively seek to replace public ones, to squash variation and plurality in the name of "freedom."

We, too, have found a kind of freedom in our collaborative endeavor, each in our respective yet ever-more conjoint institutional locations. That freedom is of a specific kind, however, and may not be seen as "freedom" in the traditional, liberatory sense: not an unencumbering, but a re-encumbering in an explosive proliferation of plural possibilities and relations.

\section{References}


Bohannan, P. (1959). The impact of money on an African subsistence economy. Journal of Economic History, 19 (4), 491-503.

Cefkin, M. (2009). Introduction: Business, anthropology, and the growth of corporate ethnography. In M. Cefkin (Ed.), Ethnography and the Corporate Encounter (pp. 1-37). Berghahn Books.

Douglas, M. (1966). Purity and Danger: An Analysis of Concepts of Pollution and Taboo. London: Routledge and Keegan Paul.

Forum, W. E. (2011). Personal Data: The Emergence of a New Asset Class. Geneva: World Economic Forum.

Gad, C. (2012). What we Talk about when we Talk about Sailor Culture: Understanding Danish Fisheries Inspection through a Cult Movie. Culture Unbound: Journal of Current Cultural Research, 4, 367-392.

Gibson-Graham, J. K. (2006). A Postcapitalist Politics. Univ Of Minnesota Press. Retrieved from http://www.amazon.com/Postcapitalist-PoliticsJ-K-Gibson-Graham/dp/0816648042

Gould, S. J. (1991). Exaptation: A crucial tool for evolutionary psychology. Journal of Social Issues, 47, 43-65.

Gould, S. J., \& Lewontin, R. C. (1979). The spandrels of San Marco and the Panglossian paradigm: a critique of the adaptationist programme. Proceedings of the Royal Society of London, series B, 205 (1161), 581-598. doi:10.1126/science.24.602.58

Graeber, D. (2011). Debt: The First 5000 Years. Brooklyn: Melville House. Green, S. (2000). Negotiating with the future: the culture of modern risk in global financial markets. Environment and Planning D: Society and Space, 18 (1), 77-89. Retrieved from http://www.envplan.com/epd/fulltext/d18/d205t.pdf

Guyer, J. I. (2004). Marginal gains: monetary transactions in Atlantic Africa. Chicago : University of Chicago Press. Retrieved from http://books.google.com/books?id=OYGROi_tp$\mathrm{YC} \&$ printsec $=$ frontcover $\& \mathrm{dq}=$ marginal + gains $\& \mathrm{~cd}=1 \# \mathrm{v}=$ onepage $\& \mathrm{q}=\& \mathrm{f}=$ false

Ho, K. (2009). Liquidated: An Ethnography of Wall Street. Duke University Press. Retrieved from http://www.amazon.com/LiquidatedEthnography-Street-Franklin-Center/dp/0822345994

Holmes, D. R., \& Marcus, G. E. (2008). Collaboration today and the reimagination of the classic scene of fieldwork encounter. Collaborative Anthropologies, 1, 81-101. doi:10.1353/cla.0.0003

Jack, W., Suri, T., \& Townsend, R. (2010). Monetary Theory and Electronic Money: Reflections on the Kenyan Experience, 96 (1), 83-122. 
Jacob, K., \& Lunn, A. (2011). Exploring the new face of retail payments. Chicago Fed Letter, The Federal Reserve Bank of Chicago, September (290a).

Jensen, C. B., \& Winthereik, B. R. (2012). Monitoring Movements: Building Partnership through Aid Infrastructures. Cambridge: MIT Press.

Kendall, J., Maurer, B., \& Machoka, P. (2012). An Emerging Platform: From money transfer system to mobile money ecosystem. Innovations: Innovations: Technology, Governance, Globalization, 6 (4), 49-64.

Langley, P. (2008) The Everyday Life of Global Finance: Saving and Borrowing in Anglo-America. Oxford: Oxford University Press.

MacKenzie, D. A. (2009). All Those Arrows. London Review of Books, 31 (12), 20-22. Retrieved from http://www.lrb.co.uk/v31/n12/donaldmackenzie/all-those-arrows

Mainwaring, S., March, W., \& Maurer, B. (2008). From meiwaku to tokushita!: lessons for digital money design from japan. Conference on Human Factors in Computing Systems. Retrieved from http://portal.acm.org/citation.cfm?id=1357058

Mas, I., \& Morawczynski, O. (2009). Designing Mobile Money Services: Lessons from M-PESA. Innovations: Technology, Governance, Globalization MIT Press, (March 2007), 77-91.

Maurer, B. (1999). Forget Locke? From Proprietor to Risk-Bearer in New Logics of Finance. Public Culture, 11 (2), 365-385. Retrieved from http://muse.jhu.edu/journals/public_culture/v011/11.2maurer.html Maurer, B. (2002). Repressed futures: financial derivatives' theological unconscious . Economy and Society , 31 (1), 15-36. Retrieved from http://www.anthro.uci.edu/faculty_bios/maurer/MaurerRepressed FuturesE\&S.pdf

Maurer, B. (2005a). Finance. In E. James G. Carrier (Ed.), A Handbook of Economic Anthropology (pp. 176-93). Cheltenham, UK: Edward Elgar.

Maurer, B. (2005b). Mutual Life, Limited: Islamic Banking, Alternative Currencies, Lateral Reason. Princeton: Princeton University Press.

Maurer, B. (2006). The Anthropology of Money. Annual Review of Anthropology, 35 (1), 15-36.

doi:10.1146/annurev.anthro.35.081705.123127

Miyazaki, H. (2007). Between arbitrage and speculation: an economy of belief and doubt. Economy and Society, 36 (3), 396-415.

doi:10.1080/03085140701428365

Moore, J. F. (2006). Business ecosystems and the view from the firm. The Antitrust Bulletin, 51 (I), 31-76. 
Pryke, M., \& Allen, J. (2000). Monetized time-space: derivatives money's "new imaginary"? Economy and Society, 29 (2), 264-284. Retrieved from http://docserver.ingentaconnect.com/deliver/connect/routledg/03085 147/v29n2/s4.pdf?expires=1270003613\&id=55927360\&titleid=737\&a ccname=University+of+California\&checksum $=46$ C4D8EE5E03AF29E6A 91D267434F91F

Riles, A. (2010). Collateral Expertise. Current Anthropology, 51 (6), 795818. doi:10.1086/657627

Riles, A. (2011). Collateral Knowledge: Legal Reasoning in the Global Financial Markets. Chicago: University Of Chicago Press.

Roitman, J. (2013). Anti-Crisis. Durham, NC: Due University Press.

Schwittay, A. (2011). The financial inclusion assemblage: subjects , technics , rationalities. Critique of Anthropology, 31 (4), 381-401. doi:10.1177/0308275X11420117

Stengers, I. (2005). Introductory notes on an ecology of practices. Cultural Studies Review, 11 (1), 183-196.

Suchman, L. (1987). Plans and Situated Actions: The Problem of HumanMachine Communication. Cambridge: Cambridge University Press.

Tett, G. (2009). Fool's gold: how the bold dream of a small tribe at J.P. Morgan was ... New York: Simon \& Schuster. Retrieved from http://books.google.com/books?id=9aQOCMEI7m8C\&pgis=1

Williams, C., Aldridge, T., \& Tooke, J. (2003). Alternative exchange spaces. Alternative Economic Spaces (pp. 151-167). London: Sage Publications.

Zaloom, C. (2006). Out of the Pits: Traders and Technology from Chicago to London. University Of Chicago Press. Retrieved from http://www.amazon.com/Out-Pits-Traders-TechnologyChicago/dp/0226978133

Bill Maurer is a cultural anthropologist who conducts research on law, property, money and finance, focusing on the technological infrastructures and social relations of exchange and payment. He is the Director for the Institute for Money, Technology and Financial Inclusion at the University of California, Irvine. Bill can be reached at wmmaurer@uci.edu.

Scott D. Mainwaring is a senior research scientist in Interaction and Experience Research (IXR) at Intel Labs and serves as the Intel PI for the new Intel Science and Technology Center (ISTC) for Social Computing at the University of California, Irvine. He may be reached at scott.mainwaring@intel.com. 
